\title{
Validity and reliability of the Greek translation of the Job Satisfaction Survey (JSS)
}

\author{
Andreas Tsounis ${ }^{1}$ and Pavlos Sarafis ${ }^{2 *}$ (D)
}

\begin{abstract}
Background: Job satisfaction is fundamental to employee well-being and successful operation of an organization. The use of effective tools for assessing it is imperative for management research. Our main purpose was to translate and adapt the Job Satisfaction Survey (JSS) questionnaire to the Greek language and to test its psychometric properties.

Methods: The tool was translated into Greek and then back into English by different bilingual translators. The Greek JSS was tested with a sample of 239 employees of various specialties in drug addiction treatment. Confirmatory Factor Analysis (CFA) for validity testing as well as internal consistency analysis for reliability testing was conducted.

Results: The results confirmed that: (a) the translated version is an accurate translation of the original, (b) CFA results indicated that the nine-factor structure model was a great choice; the factor loads were high and ranged from 0.61 to 0.90 , and (c) the reliability coefficients were satisfactory (Cronbach's alpha for eight of the nine dimensions of the Greek JSS scale ranged from 0.62 to 0.87 except for the dimension "Operating procedures" which was 0.48 , while Cronbach's alpha for the total scale was 0.87 and the Gutman Split-Half Coefficient was 0.88).

Conclusions: The findings suggested that the Greek Version of JSS is a valid and reliable tool for measuring job satisfaction in Greece. Further research for assessing its psychometric values in various samples and further analysis for studying its validity and testing its internal and external consistency and coherence might be conducted in the future.
\end{abstract}

Keywords: Job satisfaction, JSS questionnaire, Reliability, Validity, Greek translation

\section{Background}

Job satisfaction is one of the most frequently studied variables in organizational behavior research [1] and an important predictor for wellness in the work environment. It is directly linked to absenteeism and staff turnover, having at the same time a profound impact on the productivity and the effectiveness of the services that an organization provides [2-4]. Meanwhile, since the majority of people spend between one and two-thirds of their time awake in the workplace, it has a major impact on employee psychological wellbeing at home, affecting many aspects of his/her everyday life $[1,5]$.

The most-used research definition of job satisfaction was given by Locke [6], who defined it as a positive or

\footnotetext{
* Correspondence: pavlos.sarafis@cut.ac.cy

${ }^{2}$ Department of Nursing, School of Health Sciences, Cyprus University of

Technology 15, Vragadinou Str, 3041 Limassol, Cyprus

Full list of author information is available at the end of the article
}

pleasing emotional state resulting from the appraisal of one's job or job experiences. According to the above, employees form their attitudes towards their jobs by considering both their feelings and their beliefs. A simple but comprehensive definition was proposed by Spector [1], who designates job satisfaction as the extent to which someone likes (satisfaction) or dislikes (dissatisfaction) his/her job.

Job satisfaction has two dimensions, intrinsic and extrinsic. Intrinsic job satisfaction refers to how people feel about the nature of the job tasks. For example, the ability to develop one's skills, a sense of autonomy, success, achievement and control. Extrinsic job satisfaction refers to how people feel about different aspects of the work situation that are external to the work itself; for example, salary, relationships with colleagues, promotion opportunities and the quality of the job environment) $[7,8]$.

(C) The Author(s). 2018 Open Access This article is distributed under the terms of the Creative Commons Attribution 4.0 International License (http://creativecommons.org/licenses/by/4.0/), which permits unrestricted use, distribution, and reproduction in any medium, provided you give appropriate credit to the original author(s) and the source, provide a link to the Creative Commons license, and indicate if changes were made. The Creative Commons Public Domain Dedication waiver (http://creativecommons.org/publicdomain/zero/1.0/) applies to the data made available in this article, unless otherwise stated. 
Different instruments to measure job satisfaction have been developed. The main types of instruments are: global instruments that aim to assess global job satisfaction without reference to any specific facets (e.g. Job in General Scale-JIG) [9]; multidimensional instruments that refer to the facet approach (e.g. Job Diagnostic Survey-JDS) [10]; scales that may examine both global job satisfaction as well as its dimensions (e.g. Job Satisfaction Survey-JSS) [11]; instruments that measure one specific job satisfaction dimension (e.g. Pay Satisfaction Questionnaire-PSQ) [12]; whereas different instruments have been designed for jobs in general (e.g. Job Descriptive Index-JDI) or for a specific workforce (Emergency Physician Job Satisfaction Scale-EPJS) [13].

Spector constructed the JSS (Job Satisfaction Survey) which is a multidimensional instrument. Although it was originally developed for the social service sector, he argues that it can be used for other sectors as well [11]. It is one of the most frequently used job satisfaction instruments, while many studies about its psychometrical features have been conducted till today [14-16]. Besides, in a study, reviewing the psychometric quality, reliability, validity and reveal responsiveness of 29 job satisfaction instruments, JSS was one of the seven tools that met the defined and validity criteria [13].

The main purpose of the current study was to translate and investigate further the structure and to assess the factorial validity and the internal consistency of the Greek version of JSS. The results of the validity and reliability studies of an instrument assessing job satisfaction are of importance for further theoretical and empirical studies in this particular field.

\section{Methods}

\section{Participants}

The current study was conducted at the Therapy Center for Dependent Individuals (KETHEA), which is the largest rehabilitation and social reintegration network for drug addicts and their families in Greece, in the spring of 2015. Employees of all categories (administrative staff, therapy prevention staff, education - research staff, part-time trainers and other staff) comprised the sample. Questionnaires were distributed to 341 employees and were completed by 239 .

\section{Instrument}

The Job Satisfaction Survey (JSS) has 36 items with nine subscales to assess employee attitudes about their job and its different aspects. Each subscale is assessed with four items, while a total score is computed from all items. Each item is ranked on a 6-point Likert scale ranging from "strongly disagree" to "strongly agree". The 36 items are written in both directions, so about half of them must be reverse scored. The nine subscales are
Pay, Promotion, Supervision, Fringe Benefits (Monetary and nonmonetary fringe benefits), Contingent Rewards (performance-based rewards), Operating Procedures (Operating policies and required rules), Coworkers, Nature of Work, and Communication. Although the JSS was originally developed for use in human service organizations, it is applicable to a wide range of organization types in both public and private sector [11].

Scores on each of the nine-facet subscales, which in turn are based on 4 items each, can range from 4 to 24 , and scores for total job satisfaction, which are based on the sum of all 36 items, can range from 36 to 216. JSS has 19 negatively worded items, which must be reversed. A score of 6 representing strongest agreement with a negatively worded item is considered equivalent to a score of 1 representing strongest disagreement on a positively worded item [11].

As far as scoring interpretation is concerned, two approaches, normative and absolute, can be used. The normative approach would compare the target sample to the norms for the sample, which are limited in three ways: first, there is a small number of occupations and organizations represented; second, the norms are not from representative samples; and third, the norms are mainly from North America-Canada and the U.S., which means that these norms are not representative of other countries that are culturally dissimilar to North America. According to the absolute approach, scores with a mean item response (after reverse scoring) of 4 or more represent satisfaction, mean responses of 3 or less represent dissatisfaction, whereas mean scores between 3 and 4, ambivalence. So, as far as the summed scores are concerned, for the 4-item subscales, scores of 4 to 12 represent dissatisfaction, 16 to 24 represent satisfaction, and those between 12 and 16 represent ambivalence. For the 36-item total, the ranges are 36 to 108 for dissatisfaction, 144 to 216 for satisfaction, and between 108 and 144 for ambivalence. If some items are missing, an adjustment must be done, otherwise the score will be too low. The best procedure is to compute the mean score per item for the individual, and substitute that mean for the missing items. An alternative but less accurate procedure is a middle response substitution for each of the missing items, where either 3 and 4 could be used [17].

\section{Translation procedure}

The forward-backward translation, which is the most commonly applied translation process for questionnaires or inventories, was performed [18]. In the first step of the procedure, the original English of the JSS was translated into Greek language by two experienced translators. The assessment of forward translation drafts was performed by two other researchers who were asked to review each translated item independently and choose 
the most adequate in terms of clarity, common language and cultural diversity.

The second step included retranslation of the agreed Greek text to English language by a researcher who had not previously seen the original version. The backward translation was compared with the original version of the survey, and judgments about the inaccuracies were made by two other researchers. The resulting differences were finally checked by another scientist who made the necessary adjustments.

The final version of the questionnaire was given to 12 volunteer participants ( 5 male and 7 female) for pilot testing. Each participant was given a brief introduction and requested to complete the Greek version of the questionnaire independently after which each one was interviewed about its clarity and understandability. The participants confirmed that the Greek version of the JSS was coherent and easy to fill in. The Greek and the English versions of the JSS are shown in the Additional file 1.

\section{Statistical analysis}

Descriptive statistics were used. Quantitative variables were expressed as mean values (SD) and qualitative as absolute and relative frequencies. A confirmatory factor analysis (CFA) with maximum likelihood procedure was conducted in order to test how well the dimensions of the JSS fit the data. The variance of the latent constructs was fixed at one during parameter estimation and the factors were allowed to be correlated. The fit of the CFA model was assessed using the chi square $\left(\mathrm{x}^{2}\right)$, the comparative fit index (CFI), the goodness of fit index (GFI) and the root mean square error of approximation (RMSEA) [19]. For the CFI and GFI indices, values close to or greater than 0.95 are taken to reflect a good fit to the data [20]. RMSEA values of less than 0.05 indicate a good fit and values as high as 0.08 indicate a reasonable fit [20]. Pearson coefficients were used to explore intercorrelations among subscales. Reliability analysis included Cronbach's Alpha for internal consistency and Guttman Split-Half coefficient. Statistically significant level was set at .05 and the analysis was conducted using SPSS and AMOS (SPSS, Chicago, IL, USA) Statistical Software.

\section{Results}

\section{Sample characteristics}

Of the 341 questionnaires distributed, 239 were returned fully completed (70.09\% response rate). More than $64 \%$ of the study participants were female and the majority were aged between 35 and 39 (34.3\%) or between 40 and 50 years (45.2\%). As far as educational level is concerned, the majority was university graduates, while $38.1 \%$ had post-graduate studies. Concerning working position, the majority worked as Therapy - Prevention staff (56.1\%), followed by Administrative staff (20.1\%), Education - Research staff (12.1\%), Part-time Trainers (7.5\%) and other staff (4.2\%). As regards length of service, $37.2 \%$ of study participants had worked from 11 to 15 years, $28 \%$ from 6 to 10 years, $13.8 \%$ from 16 to 20 years $12.1 \%$ from 0 to 5 years, $7.1 \%$ from 20 to 25 years, while $1.7 \%$ had worked for more than 26 years (Table 1).

\section{Descriptive statistics}

The highest mean from the scale was in the dimension of "Nature of work" (Mean =18.8), while the lowest mean was recorded in the dimension of "Pay" (Mean =9.5). Mean scores were comparable with the data of the original study of Spector (1985), where the highest mean was in the dimension of "Supervision" $(\mathrm{M}=19.9)$ and the lowest in "Pay" (Mean = 10.5). The general job satisfaction mean in the Greek sample was lower $($ Mean $=128.3)$ than that of the American sample $($ Mean $=133.1)$ (Table 2).

Table 1 Demographic features of the Sample

\begin{tabular}{|c|c|c|c|}
\hline \multirow[t]{2}{*}{ Characteristics } & \multicolumn{3}{|l|}{ Participants $(n=239)$} \\
\hline & & $\mathrm{N}$ & $\%$ \\
\hline \multirow[t]{2}{*}{ Gender } & Women & 153 & 64 \\
\hline & Men & 86 & 36 \\
\hline \multirow[t]{5}{*}{ Age (years) } & $25-29$ & 3 & 1,3 \\
\hline & $30-34$ & 20 & 8.4 \\
\hline & $35-39$ & 82 & 34.3 \\
\hline & $40-49$ & 108 & 45.2 \\
\hline & $>50$ & 26 & 10.9 \\
\hline \multirow[t]{6}{*}{ Educational level } & Post-graduate studies & 91 & 38.1 \\
\hline & University graduate & 85 & 35.6 \\
\hline & $\begin{array}{l}\text { Technological Institutions } \\
\text { graduate }\end{array}$ & 23 & 9.6 \\
\hline & $\begin{array}{l}2 \text { year Technical School } \\
\text { (Post Secondary) }\end{array}$ & 11 & 4.6 \\
\hline & Upper Secondary Education & 23 & 9.6 \\
\hline & Low Secondary Education & 6 & 2.5 \\
\hline \multirow[t]{5}{*}{ Specialty } & Administrative staff & 48 & 20.1 \\
\hline & Therapy - Prevention staff & 134 & 56.1 \\
\hline & Education - Research staff & 29 & 12.1 \\
\hline & Part-time Trainers & 18 & 7.5 \\
\hline & Other Staff & 10 & 4.2 \\
\hline \multirow{6}{*}{$\begin{array}{l}\text { Professional Experience } \\
\text { (years) }\end{array}$} & $0-5$ & 29 & 12.1 \\
\hline & $6-10$ & 67 & 28 \\
\hline & $11-15$ & 89 & 37.2 \\
\hline & $16-20$ & 33 & 13.8 \\
\hline & $20-25$ & 17 & 7.1 \\
\hline & $>26$ & 4 & 1.7 \\
\hline
\end{tabular}


Table 2 Comparative presentation of mean scores and Standard Deviation of JSS in U.S.A. and Greece

\begin{tabular}{|c|c|c|c|c|}
\hline \multirow[b]{2}{*}{ Subscale } & \multicolumn{2}{|c|}{$\begin{array}{l}\text { American Sample } \\
(N=3067) \\
\text { Spector (1985) }\end{array}$} & \multicolumn{2}{|c|}{$\begin{array}{l}\text { Greek Sample } \\
(N=239)\end{array}$} \\
\hline & Mean & S.D. & Mean & S.D. \\
\hline Pay & 10.5 & 5.1 & 9.5 & 3.6 \\
\hline Promotion & 11.5 & 5.1 & 10.1 & 3.9 \\
\hline Supervision & 19.9 & 4.6 & 18.6 & 4.6 \\
\hline Fringe Benefits & 13.1 & 5.0 & 11.6 & 4.6 \\
\hline Contigent Rewards & 13.4 & 5.1 & 14.0 & 4.1 \\
\hline Operating Procedures & 12.5 & 4.6 & 13.1 & 3.6 \\
\hline Coworkers & 18.8 & 3.7 & 18.1 & 3.3 \\
\hline Nature of Work & 19.2 & 4.4 & 18.8 & 3.3 \\
\hline Communication & 14.0 & 5.0 & 14.6 & 4.3 \\
\hline Total Satisfaction & 133.1 & 27.9 & 128.3 & 20.5 \\
\hline
\end{tabular}

\section{Statistical analysis of validity}

The CFA assessed the fit of the nine-factor structure and the model fitted the data well as defined from the RMSEA, CFI and GFI values that were equal to 0.055, 0.951 and 0.946 , respectively. None of the item cross loadings exceeded the item loadings on the intended latent construct. Factor loadings were high and ranged from 0.61 to 0.90 indicating a strong association between the latent factors and their respective items.

Table 3 indicates that intercorrelations among subscales range between 0.13 and 0.56 . More specifically, correlations were high in three cases, while there were also six medium and six low intercorrelations. The above finding resembles Spector' s results [11], which also reported low to medium intercorrelations among subscales, ranging from .11 to .59 .

\section{Statistical analysis of reliability}

Cronbach alpha coefficient for each dimension of the Greek JSS scale ranged from 0.62 to 0.87 except in the dimension "Operating procedures" where it was 0.48 . Overall, the reliability estimate for the total scale was 0.87 for the thirty-six items of the adapted scale. The comparative presentation of Cronbach's alpha coefficients between the American sample of Spector's original study and the Greek sample of the current study is shown in Table 4.

Split-half reliability was also done by dividing the measure into two halves; (a) consisted of first 18 items and (b) consisted of the remaining 18 items of the scale. The findings showed that JSS had good split-half reliability as assessed through Guttman Split-Half Coefficient (.876) (Table 5).

\section{Discussion}

The purpose of the current study was the translation of the JSS into Greek and the examination of its psychometric properties. The JSS is a widely used tool which has been translated in more than nineteen languages [17]. Cultural variability could seriously affect the design and adaptation of a questionnaire [21]. Previous studies' results, examining the psychometric properties of JSS in different countries and cultural contexts, support Spector and Wimalasiri's [22] claim that cultural differences are found to be underlying the JSS structure. In some cases like Turkey [15] and Pakistan [16], factor structures of the translated versions were found to be similar to the original survey. On the other hand, studies in other countries led to different structure models. In a study in Iranian population, seven factors were identified [23] in a study on Malaysian employees, eight, four and three factor analysis solutions were reported [24], in a study in Uganda, a four-factor solution was the best model [25], while in the Ukraine the best model came out to be a three-facet model [14]. Concerning the validity of the Greek version, the results of CFA of our study indicated that the nine-factor structural model of the JSS was well-adapted and consistent with the original version of the tool. From the nine facets of JSS, nature of

Table 3 Pearson Correlations among JSS Subscales in Greek Data

Pay Promotion Supervision Fringe Benefits Contingent Rewards Operating Procedures Coworkers Nature of Work

Pay

Promotion $\quad .32^{*}$

Supervision $\quad-.08 \quad .26^{*}$

Fringe Benefits $\quad .48^{*} .32^{*} \quad-.01$

Contingent Rewards $\quad .51^{*} \quad .42^{*} \quad .37^{*} \quad .38^{*}$

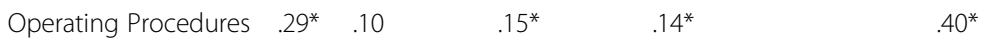

$\begin{array}{lllll}\text { Coworkers } & -.07 & .13^{*} & .56^{*} & -.06\end{array}$

Nature of Work $\quad .01 \quad .23^{*} \quad .34^{*} \quad-.07$

$\begin{array}{lllll}\text { Communication } & .11 & .26^{*} & .47^{*} & .14^{*}\end{array}$

${ }^{*} p<0.050$ 
Table 4 Comparative presentation of internal consistency coefficients of JSS in U.S.A. and Greece

\begin{tabular}{|c|c|c|c|c|}
\hline \multirow[b]{2}{*}{ Subscale } & \multicolumn{2}{|c|}{$\begin{array}{l}\text { American Sample } \\
\text { Spector (1985) }\end{array}$} & \multicolumn{2}{|c|}{ Greek Sample } \\
\hline & $\bar{N}$ & Cronbach Alpha & $\bar{N}$ & Cronbach Alpha \\
\hline Pay & 2870 & 0.75 & 239 & 0.62 \\
\hline Promotion & 2870 & 0.73 & 239 & 0.67 \\
\hline Supervision & 2870 & 0.82 & 239 & 0.87 \\
\hline Fringe Benefits & 2870 & 0.73 & 239 & 0.73 \\
\hline Contigent Rewards & 2870 & 0.76 & 239 & 0.71 \\
\hline Operating Procedures & 2870 & 0.62 & 239 & 0.48 \\
\hline Coworkers & 2870 & 0.60 & 239 & 0.67 \\
\hline Nature of Work & 2870 & 0.78 & 239 & 0.74 \\
\hline Communication & 2870 & 0.71 & 239 & 0.71 \\
\hline Total Satisfaction & 2870 & 0.91 & 239 & 0.87 \\
\hline
\end{tabular}

work, supervision and promotion are the subscales that fit well both in cases that validation process in different countries revealed consistency with the original nine facet version $[15,16]$ and in cases that some of the JSS subscales poorly explained some of the tool aspects or led to different factorial structure [14, 23]. On the contrary, the structure of the other JSS factors seems to be strongly affected from cross-cultural differences that in many cases lead to factor variation.

As far as reliability and internal consistency are concerned, values show that the scale items are consistent with one another in as many as eight of the nine subscales. The measures whose Cronbach's Alpha exceeds 0.60 are considered to be the reliable ones [26]. In the current study, the total scale and all subscales but one were over 0.60. This finding shows that there is adequate internal consistency for the JSS total and for its subscales except the "operating procedures" facet. Internal consistency values for the rest 8 subscales and the total

Table 5 Split-Half reliability analysis

\begin{tabular}{|c|c|c|c|}
\hline & & Split-Half Reliabili & \\
\hline \multirow[t]{5}{*}{ Cronbach's Alpha } & \multirow[t]{2}{*}{ Part 1} & Value & .747 \\
\hline & & $\mathrm{N}$ of Items & $18(a)^{a}$ \\
\hline & \multirow[t]{3}{*}{ Part 2} & Value & .776 \\
\hline & & $\mathrm{N}$ of Items & $18(b)^{a}$ \\
\hline & & Total N of Items & 36 \\
\hline \multicolumn{3}{|l|}{ Correlation Between Forms } & .781 \\
\hline \multirow[t]{2}{*}{ Spearman-Brown Coefficient } & & Equal Length & .877 \\
\hline & & Unequal Length & .877 \\
\hline \multicolumn{3}{|l|}{ Guttman Split-Half Coefficient } & .876 \\
\hline
\end{tabular}

scale were consistent with Spector's original study findings (Table 4). Moreover, according to the findings, the Greek version of the JSS has good split-half reliability (0.88).

\section{Limitations}

Like any other research in social sciences, the current study also has certain limitations. First, the sample was relatively small. Second, the data was collected only from employees working in drug addiction treatment; therefore, it can't be generalized for all employees providing healthcare services. Third, almost half of KETHEA employees took part in the study, as they were the only ones available. Therefore, the extent to which results may be generalized is limited and should be treated cautiously. Forth, we did not estimate the convergent validity by comparing JSS with a similar tool and the discriminant validity by comparing JSS with a tool designed to measure a different concept. Finally, the use of the test retested the reliability method to examine the degree to which the results are consistent over time, as it was not feasible in the current field of research.

\section{Conclusions}

Future studies might apply the JSS Greek version to other samples that will include a diverse population from both the public and private sector and beyond social services, in order to establish valuable results and determine the norms of the scale for a wider range of professionals and organizations. In addition, future researchers may examine the criterion, convergent and discriminant validity of the JSS. However, despite the above limitations, it is our hope that the Greek JSS will be used in the future in studies related to job satisfaction.

\section{Additional file}

Additional file 1: Simultaneous presentation of the English and Greek version of JSS. (DOCX 23 kb)

\section{Abbreviations}

CFA: Confirmatory Factor Analysis; CFI: Comparative Fit Index; EPJS: Emergency Physician Job Satisfaction Scale; GFI: Goodness of Fit Index; JDI: Job Descriptive Index; JDS: Job Diagnostic Survey; JIG: Job in General Scale; JSS: Job Satisfaction Survey; KETHEA: Therapy Center for Dependent Individuals; PSQ: Pay Satisfaction Questionnaire; RMSEA: Root Mean Square Error of Approximation

\section{Funding}

This research did not receive any specific grant from funding agencies in the public, commercial, or not-for-profit sectors.

\section{Availability of data and materials}

A confidentiality agreement with participants prevent us from sharing the data. 


\section{Authors' contributions}

AT and PS both conceived the study, collected data and performed statistical analysis. AT prepared the manuscript. PS has edited the manuscript and made critical contributions to the interpretation of data as well. Both authors have read and approved the final manuscript.

\section{Ethics approval and consent to participate}

Research and Evaluation Committee of KETHEA granted permission for conducting the research. The study participants received a cover letter with information regarding the study aim, that participation was voluntary and that data would be treated confidentially. Hence, returning the questionnaire was interpreted as informed consent.

\section{Competing interests}

The authors declare existence of no competing interests.

\section{Publisher's Note}

Springer Nature remains neutral with regard to jurisdictional claims in published maps and institutional affiliations.

\section{Author details}

'Aristotle University of Thessaloniki, School of Psychology, Thessaloniki, Greece. ${ }^{2}$ Department of Nursing, School of Health Sciences, Cyprus University of Technology 15, Vragadinou Str, 3041 Limassol, Cyprus.

Received: 30 October 2017 Accepted: 1 June 2018

Published online: 08 June 2018

\section{References}

1. Spector PE. Job satisfaction: application, assessment, causes, and consequences. Thousand oaks, CA: Sage; 1997.

2. Pitts DW. Diversity management, job satisfaction, and performance: evidence from US Federal Agencies. Public Admin Rev. 2009;69:328-38. https://doi.org/10.1111/j.1540-6210.2008.01977.x.

3. Franek $M$, Vecera J. Personal characteristics and job satisfaction. E \& M Ekonomie a Management. 2008;11:63-76.

4. Saari LM, Judge TA. Employee attitudes and job satisfaction. Hum Resource Manage. 2004;43:395-407. https://doi.org/10.1002/hrm.20032.

5. Bruck CS, Allen TD, Spector PE. The relation between work-family conflict and job satisfaction: a finer-grained analysis. J Vocat Behav. 2002;60:336-53. https://doi.org/10.1006/jvbe.2001.1836.

6. Locke EA. The nature and causes of job satisfaction. In: Dunnette MD, editor. Handbook of industrial and organizational psychology. Chicago: Rand McNally; 1976. p. 1297-349.

7. Hirschfield RR. Does revising the intrinsic and extrinsic subscales of the Minnesota satisfaction. Questionnaire short form make a difference? Educ Psychol Meas. 2000;60:255-70. https://doi.org/10.1177/00131640021970493.

8. Shim S, Lusch R, O'Brien M. A hierarchical model of values, leadership, job satisfaction and commitment: human resources management implications for the retail industry. J Marketing Channels. 2002;10:65-87. https://doi.org/ 10.1300/J049v10n01 05.

9. Ironson GH, Smith PC, Brannick MT, Gibson WM, Paul KB. Construction of a job in general scale: a comparison of global, composite, and specific measures. J Appl Psychol. 1989;74:193-200.

10. Hackman JR, Oldham GR. Development of the job diagnostic survey. J Appl Psychol. 1975;60:159-70. https://doi.org/10.1037/h0076546.

11. Spector PE. Measurement of human service staff satisfaction: development of the job satisfaction survey. Am J Community Psychol. 1985;13:693-713. https://doi.org/10.1007/BF00929796.

12. Heneman HG, Schwab DP. Pay satisfaction: its multidimensional nature and measurement. Aust J Psychol. 1985;2:129-41. https://doi.org/10.1080/ 00207598508247727

13. Van Saane N, Sluiter JK, Verbeek JH, Frings-Dresen MH. Reliability and validity of instruments measuring job satisfaction-a systematic review. Occup Med. 2003;53:191-200. https://doi.org/10.1093/occmed/kqg038.

14. Astrauskaite M, Vaitkevicius R, Perminas A. Job satisfaction survey: a confirmatory factor analysis based on secondary school teachers' sample. Int J Bus Manage. 2011;6:41-50. https://doi.org/10.5539/ijbm.v6n5p41.

15. Yelboga A. Validity and reliability of the Turkish version of the job satisfaction survey (JSS). World App Sci J. 2009;6:1066-72.
16. Shahzad S, Begum N. (2011). Urdu translation and psychometric properties of the job satisfaction survey (JSS) in Pakistan. Int J Educ Psychol Assess. 2011;9:57-74.

17. Spector P. Job Satisfaction Survey, JSS Page. JSS translations. http://shell.cas. usf.edu/ pspector/scales/jsstranslate.html Accessed 5 Jan 2017.

18. Yu DS, Lee DT, Woo J. Issues and challenges of instrument translation. West J Nurs Res. 2004;26:307-20. https://doi.org/10.1177/0193945903260554.

19. Mueller R. Basic principles of structural equation modeling. New York: Springer; 2000.

20. Hu L, Bentler P. Cutoff criteria for fit indices in covariance structure analysis: conventional criteria versus new alternatives. Struct Equ Modeling. 1999:6:1-55. https://doi.org/10.1080/10705519909540118.

21. Johnson TP, Cho YI, Holbrook AL, O'Rourke D, Warnecke RB, Chavez N Cultural variability in the effects of question design features on respondent comprehension of health surveys. Ann Epidemiol. 2006;16:661-8. https://doi. org/10.1016/j.annepidem.2005.11.01.

22. Spector PE, Wimalasiri J. A cross-cultural comparison of job satisfaction dimensions in the United States and Singapore. Appl Psychol. 1986;35:147-58. https://doi.org/10.1111/j.1464-0597.1986.tb00909.x.

23. Gholami Fesharaki M, Talebiyan D, Aghamiri Z, Mohammadian M. Reliability and validity of" job satisfaction survey" questionnaire in military health care workers. Iran J. Mil Med. 2012:13:241-6.

24. Ibrahim RZA, Ohtsuka K, Dagang MM, Bakar AA. Job satisfaction among Malaysian employees: an application of Spector's job satisfaction survey in the south east Asian context. Jurnal Pengurusan. 2014;41:69-79.

25. Ibrahim Abaasi M. Psychometric evaluation of job satisfaction scale in Ugandas teacher population sample. Glob J Hum Soc Sci Res. 2016;16:56-64.

26. Nunnally JC, Bernstein $\mathrm{H}$. Psychometric theory. 3rd ed. New York: McGraw-Hill; 1994.

\section{Ready to submit your research? Choose BMC and benefit from:}

- fast, convenient online submission

- thorough peer review by experienced researchers in your field

- rapid publication on acceptance

- support for research data, including large and complex data types

- gold Open Access which fosters wider collaboration and increased citations

- maximum visibility for your research: over $100 \mathrm{M}$ website views per year

At BMC, research is always in progress.

Learn more biomedcentral.com/submissions 